\title{
The effect of human growth hormone on the carbohydrate units in arterial basement membrane-like material
}

\author{
Thomas Ledet ${ }^{1}$ and Lene Heickendorff ${ }^{2}$ \\ ${ }^{1}$ Research Laboratory for Biochemical Pathology, Institute for Experimental Clinical Research, University of Aarhus, Aarhus Kommunehospital, \\ DK-8000 Aarhus C., Denmark and ${ }^{2}$ Department of Clinical Biochemistry, Aarhus Amtssygehus, DK-8000 Aarhus C., Denmark
}

(Correspondence should be addressed to T Ledet, Research Laboratory for Biochemical Pathology, Norrebrogade 44, building 3 , Aarhus Kommunehospital, DK-8000 Aarhus C., Denmark; Email: Ledet@Biobase.dk)

\begin{abstract}
Objective: The present study focuses on the pathogenesis of the large vessel disease in diabetes. The arterial wall from diabetic individuals displays characteristic alterations of the extracellular matrix. Other observations show that the metabolism is changed with increased levels of growth hormone in diabetes.

Design: The effects of growth hormone on the carbohydrate composition in the basement membrane around the arterial smooth muscle cells were investigated.

Methods: Basement membrane material was obtained from cultures of smooth muscle cells by sonication and differential centrifugation after labeling with either $\left[{ }^{3} \mathrm{H}\right]$ glucose or $\left[{ }^{3} \mathrm{H}\right]$ glucosamine. The proportions of galactose, glucose, mannose, xylose, fucose and glucosamine were evaluated after addition of $45.45 \mathrm{pmol} / \mathrm{l}$ human growth hormone. Also, the proportion of glycopeptides generated from the basement membrane was analyzed after fractionation on a combination of a Concanavalin A and a Pea Sepharose column.

Results: The proportion of galactose and glucose was changed, and the incorporation of $\left[{ }^{3} \mathrm{H}\right]$ glucosamine was reduced. The proportion of glycopeptides containing high mannose moities was increased as well as that of triantinary glycopeptides with internal fucose residues.

Conclusion: The current in vitro data indicates that growth hormone may change the carbohydrate composition of the arterial basement membrane.
\end{abstract}

European Journal of Endocrinology 142 631-635

\section{Introduction}

It is well established that growth hormone is one important regulator of the metabolism of glucose and lipid in vivo (1). This may be of particular interest in relation to the late manifestations of the diabetic angiopathy in which accumulation and changes in the basement membrane are characteristic phenomena (2). The carbohydrates in the arterial basement membrane are known to be important for the degradation (3). It is therefore of relevance to evaluate the influence of growth hormone on the carbohydrate composition of the arterial basement membrane. This seems reasonable, keeping in mind that, in diabetic patients, the serum growth hormone concentration is increased (4).

The effect of growth hormone is complex and varies greatly according to the conditions under which experiments are performed in vitro. The direct action of growth hormone on protein metabolism may be a stimulation of the local synthesis as seen in the human forearm (5). It has been shown to decrease the insulin- stimulated glucose utilization and metabolism in cultured human fibroblast (6). Prolonged elevation of the concentration of growth hormone in plasma decreases the sensitivity to the insulin-induced glucose transport in skeletal muscles (1). These various observations suggest the presence of a stimulated nonoxidative glucose utilization, indicated by the reduced oxidation and uptake in a muscle despite an unchanged endogenous glucose production (7). However, it appears from the literature that the influence of growth hormone on the carbohydrate composition in glycoproteins has not been studied previously.

It is characteristic that the arterial smooth muscle cells are covered by basement membrane-like material (BM-like material), which is a pericellular structure containing important constituents such as laminin, type IV collagen, fibronectin and heparan sulfate proteoglycan (8-10). All these components contain carbohydrate units in various amounts and the susceptibility for degradation of the basement membrane by protease has been shown also to be dependent 
on the above-mentioned sugar units (3). Previous studies have demonstrated that growth hormone is able to increase the accumulation of BM-like material in cultures of arterial smooth muscle cells (11).

In the present study, we have attempted to elucidate the effect of growth hormone on the composition of glycopeptides. These were obtained from the pericellular BM-like material covering the arterial smooth muscle cells. We have also focused on the distribution of monosaccharides and amino sugars after administration of growth hormone to the cell culture. It was found that growth hormone had a significant effect on the carbohydrate composition in the BM-like material.

\section{Materials and methods}

\section{Cell cultures}

Non-trypsinized primary cultures of arterial smooth muscle cells were grown out from rabbit aorta as described earlier (8). The experiments were performed on cultures after five weeks of growth when 'the stationary growth phase' was reached.

\section{Incubation conditions}

Cell cultures were preincubated for $24 \mathrm{~h}$ in the usual growth medium, supplemented with $45.45 \mathrm{pmol} / \mathrm{l}$ recombinant human growth hormone (hGH). A previous study has shown that the maximum effect of growth hormone was observed at $45.45 \mathrm{pmol} / \mathrm{l}$ (11, 12). The growth medium consisted of basal medium eagle, Hank's balanced salt solution with $10 \%$ serum (rabbit), ascorbic acid $(50 \mu \mathrm{g} / \mathrm{ml})$, antibiotic (neomycin sulfate) and a concentration of unlabeled glucose of $5.5 \mathrm{mmol} / \mathrm{l}$. Using radioactive glucose and glucosamine it is possible to label glycosaminoglycans as well as asparagine and serine bound carbohydrate chains. After termination of the $24 \mathrm{~h}$ preincubation period with hGH, new medium was applied containing $45.45 \mathrm{pmol} / \mathrm{l} \mathrm{hGH}$ and $5 \mu \mathrm{Ci} / \mathrm{ml}\left[6-{ }^{3} \mathrm{H}\right]$ glucose. The whole medium with growth hormone and labeled glucose was changed after an incubation period of $24 \mathrm{~h}$ in order to get sufficient labeling of glycopeptides. There was no difference in the glucose concentration between the cultures. Parallel incubation of controls was performed and the growth period was extended for an additional $24 \mathrm{~h}$. Some of the cell cultures were also labeled with $0.1 \mu \mathrm{Ci} / \mathrm{ml}$ $\left[6-{ }^{3} \mathrm{H}\right]$ glucosamine using a preincubation period as described above, labeling for $24 \mathrm{~h}$ and a growth hormone concentration of $45.45 \mathrm{pmol} / \mathrm{l}$ in the medium.

\section{Preparation of BM-like material}

After metabolic labeling, the BM-like material was isolated from the cell layer by sonication and differential centrifugation using the modified technique of Spiro (13) as previously described (8). In the presence of proteinase inhibitors $(0.5 \mathrm{mmol} / \mathrm{l}$ N-ethylmaleimide, $0.5 \mathrm{mmol} / \mathrm{l}$ phenylmethylsulfonyl fluoride, $1 \mathrm{mmol} / \mathrm{l}$ benzamidine-HCl) the cells were sonicated for $3 \times 30 \mathrm{~s}$ in $1 \mathrm{~mol} / \mathrm{l} \mathrm{NaCl}$ buffered with $10 \mathrm{mmol} / \mathrm{l}$ Tris $-\mathrm{HCl}$ at $4{ }^{\circ} \mathrm{C}$. The BM-like material was sedimented by centrifugation at $2100 \mathrm{~g}$ for $10 \mathrm{~min}$ at $4^{\circ} \mathrm{C}$. The pellet was sequentially washed three times in $1 \mathrm{~mol} / \mathrm{l} \mathrm{NaCl}$, two times in $0.15 \mathrm{~mol} / \mathrm{l} \mathrm{NaCl} \pm 2$, and finally once in distilled $\mathrm{H}_{2} \mathrm{O}$. The material obtained (200-500 $\mu \mathrm{g}$ per culture flask) was freeze-dried and stored at $-18^{\circ} \mathrm{C}$ until use.

\section{Fractionation of glycopeptides}

Isolated BM-like material labeled with $\left[{ }^{3} \mathrm{H}\right]$ glucose was treated with proteinase (enzyme/substrate ratio $1: 10 \mathrm{w} /$ w) (14). The digest was desalted on a column of Sephadex G-15 $(1 \times 60 \mathrm{~cm})$ in $7 \%$ propanol in $\mathrm{H}_{2} \mathrm{O}$. The void fractions were pooled and freeze-dried. The glycopeptides were fractionated on a ConA Sepharose 4B column $(0.6 \times 10 \mathrm{~cm})$ in $0.1 \mathrm{~mol} / \mathrm{l}$ Tris-HCl, $1 \mathrm{mmol} / \mathrm{l} \mathrm{CaCl}_{2}$, $1 \mathrm{mmol} / \mathrm{l} \mathrm{MgCl}_{2}, \mathrm{pH} 8.0$, followed by $10 \mathrm{mmol} / \mathrm{l} \alpha-$ methylglucoside at room temperature at a flow rate of approximately $1 \mathrm{ml} / \mathrm{min}$. Finally, $0.1 \mathrm{~mol} / \mathrm{l} \alpha$-methylmannoside was applied at a temperature of $60^{\circ} \mathrm{C}(15)$.

In another series of experiments, the non-retained peak from the ConA Sepharose 4B column was desalted as described above, and further fractionated on a Pea Sepharose 4B column in the buffer system, also described above, using $10 \mathrm{mmol} / \mathrm{l}$ glycopyranoside (15, 16).

The average recovery was $90 \%$ for the gel filtration and between $80-92 \%$ for the fractionation of the glycopeptides.

\section{Measurements of neutral and amino sugars}

The effect of hGH upon the content of neutral and amino sugars within the extracellular BM-like material was also investigated on cultures labeled with $\left.{ }^{3} \mathrm{H}\right] \mathrm{glu}-$ cose. Neutral sugars were liberated by hydrolysis in $1 \mathrm{~mol} / \mathrm{l} \mathrm{HCl}$ for $5 \mathrm{~h}$ at $100{ }^{\circ} \mathrm{C}$ under $\mathrm{N}_{2}$ in sealed tubes. Neutral and amino sugars were obtained by passage of the hydrolysate through coupled columns of AG 50WX4 (Bio-rad Labs, CA, USA) $\left(\mathrm{H}^{+}\right.$form: 200-400 mesh) and AG 1-X4 (format form) (17). The monosaccharides were then separated as borate complexes on an anionexchange chromatography using DA-X4-11 Resin (Dionex Corporation, USA) as earlier described (18). In order to evaluate the incorporation into hexosamine, the BM-like material was hydrolyzed in $4 \mathrm{~mol} / \mathrm{l} \mathrm{HCl}$ for $5 \mathrm{~h}$ at $100{ }^{\circ} \mathrm{C}$, also in sealed tubes. The amino sugars were eluted from the cationic resin (AG 50W-X4) and measured using liquid scintilation counting. The average recovery was $77 \%$ when standard mixture of hexoses were subjected to the whole procedure (hydrolysis included) and $88 \%$ when standards of hexosamine were analyzed by this procedure. 


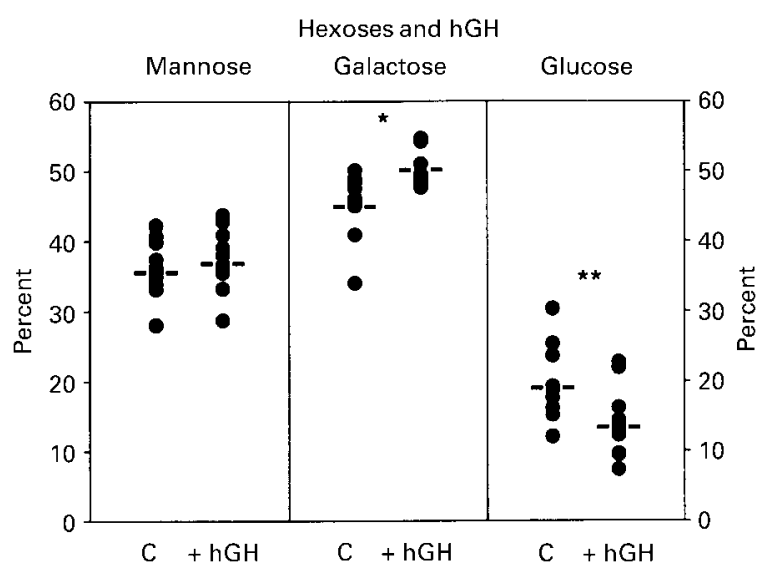

Figure 1 The effect of $45.45 \mathrm{pmol} / /$ human growth hormone on the proportion of monosaccharides in the arterial basement membrane isolated from smooth muscle cells in culture after $48 \mathrm{~h}$ incubation with $\left[{ }^{3} \mathrm{H}\right]$ glucose. ${ }^{*}=2 P<0.01,{ }^{\star *}=2 P<0.03 . \mathrm{C}=$ control. Means are shown as horizontal dashed lines.

\section{Statistical methods}

The results were based on cultures from at least two aortas. Student's $t$-test was used and a $2 P$ value of less than 0.05 was considered as the limit of significance. The data are presented as $\overline{\mathrm{X}} \pm$ S.D.

\section{Results}

The effect of hGH on the distribution of neutral monosaccharides in the arterial extracellular BM-like material was evaluated using $\left[{ }^{3} \mathrm{H}\right]$ glucose as a precursor. A significant shift could be seen in the galactose:

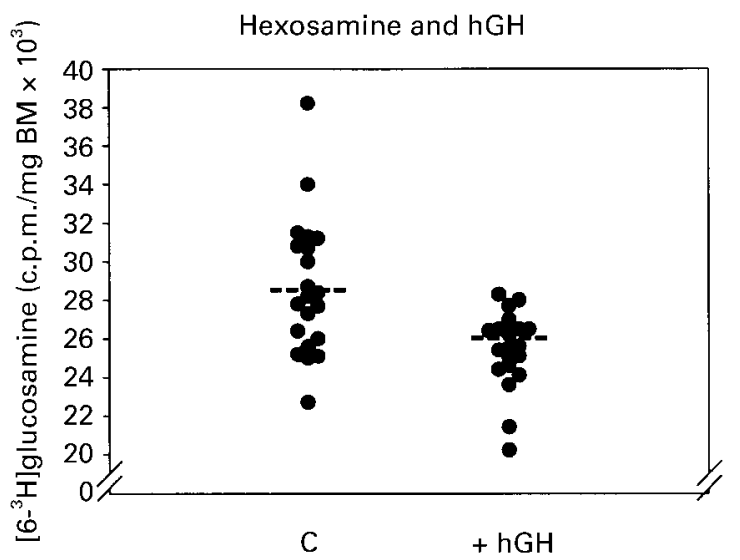

Figure 2 The incorporation of radioactive $\left[6-{ }^{3} \mathrm{H}\right]$ glucosamine into the arterial basement membrane isolated from smooth muscle cells grown in culture with $45.45 \mathrm{pmol} / \mathrm{l}$ human growth hormone for $24 \mathrm{~h}$. The difference between the groups was significant, $2 P<0.01$. $\mathrm{C}=$ control. Means are shown as horizontal dashed lines.

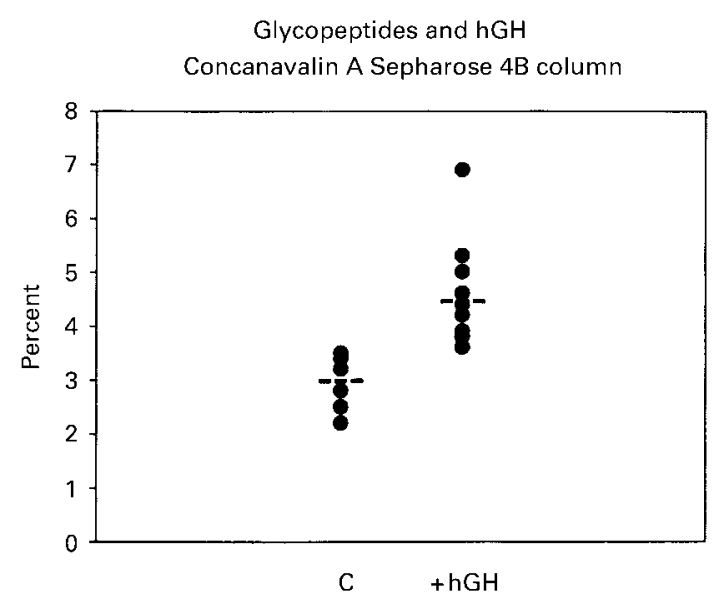

Figure 3 The effect of $45.45 \mathrm{pmol} / \mathrm{l}$ growth hormone on the proportion of glycopeptides released from ConA Sepharose 4B column with $0.1 \mathrm{~mol} / \mathrm{l}$ mannopyranoside. The glycopeptides isolated from the basement membrane from arterial smooth muscle cells in cultures were radiolabeled with $\left[{ }^{3} \mathrm{H}\right]$ glucose for $48 \mathrm{~h}$. The difference between the groups was significant, $2 P<0.02$. $\mathrm{C}=$ control. Means are shown as horizontal dashed lines.

$45.52 \% \pm 4.81 \sim 50.71 \% \pm 2.89(2 P<0.01$, Fig. 1$)$ as well as in the glucose: $19.57 \% \pm 5.47 \sim 13.97 \% \pm$ 5.10 in fractions from the BM-like material after treatment with hGH $(2 P<0.03$, Fig. 1$)$. The incorporation into mannose was unchanged. Only insignificant proportions of labeled fucose, xylose and amino sugars were released after labeling with radioactive glucose. Using radioactive glucosamine as a precursor, it was shown clearly that incorporation into the BM-like material was reduced significantly by growth hormone (Fig. $2,2 P<0.01, n=21$ ).

The composition of glycopeptides was also affected by $\mathrm{hGH}$, as it appeared after the lectin-agarose affinity chromatography. The major part of the labeled glycopeptides did not bind to the ConA Sepharose 4B column and no difference between hGH-treated and control cultures was found. However, it was observed that $45.45 \mathrm{pmol} / \mathrm{l}$ hGH enhanced (by approximately 30\%) the proportions of radioactive glycopeptides released from the column with $0.1 \mathrm{~mol} / \mathrm{l}$ mannopyranoside $(3.06 \% \pm 0.48 \sim 4.53 \% \pm 0.97,2 P<0.02)$ (Fig. 3). The quantity of glycopeptides leaving the column after the addition of $1 \mathrm{mmol} / \mathrm{l}$ glycopyranoside was not influenced by growth hormone.

When the unbound glycopeptides from the ConA Sepharose $4 \mathrm{~B}$ column were further fractionated on a Pea Sepharose 4B column, only a minor part of the glycopeptides was retained. However, the quantity of radioactivity released by $10 \mathrm{mmol} / \mathrm{l}$ glycopyranoside from the Pea Sepharose 4B column was significantly increased when hGH-treated cultures were compared with control cultures $(2.8 \% \pm 2.3 \sim 7.9 \% \pm 5.2$, $2 P<0.01$ ) (Fig. 4). 


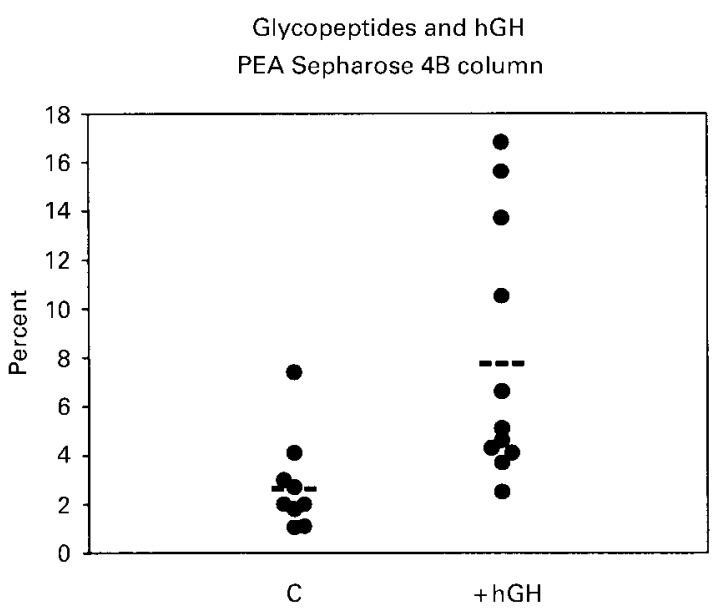

Figure 4 The effect of $45.45 \mathrm{pmol} / /$ human growth hormone on the proportion of glycopeptides which were not bound by a ConA Sepharose 4B column, but retarded in a Pea Sepharose 4B column and released with $10 \mathrm{mmol} / \mathrm{l}$ glycopyranoside. The glycopeptides isolated from the arterial basement membrane surrounding the smooth muscle cells in cultures were radiolabeled with $\left[{ }^{3} \mathrm{H}\right]$ glucose for $48 \mathrm{~h}$. The difference between the groups was significant, $2 P<0.01$. $C=$ control. Means are shown as horizontal dashed lines.

\section{Discussion}

The present study demonstrates that growth hormone, at a physiological level, has a significant effect on the carbohydrate composition in the extracellular located BM-like material which surrounds the arterial smooth muscle cells.

It is important to note that the observed changes in the incorporation into galactose and glucose refer only to the relative values. A key question is whether the perceived alterations of the monosaccharides are results of changes in the proportion of peptides or of changes in the carbohydrates per se. In a previous study, we have not been able to identify any alterations in the peptide pattern after SDS-PAGE of material isolated from hGHtreated cultures (11). These observations indicate that the enlisted deviations are not a consequence of the presence of new sugar-rich peptides or major extensions of carbohydrate chains located to a few peptides, which in both situations may have altered the mobility of the peptides. Therefore, it seems reasonable to consider the results obtained to be a consequence of carbohydrate changes. The present data also suggest that collagen types IV and V may be involved, since these types of proteins belong to the very few in which glucose is seen. This glucose is bound to galactose in the glucosegalactose-hydroxylysine unit (19). A previous analysis has demonstrated that collagen types I and III are not present in our basement membrane preparation (8). It is noteworthy, that the alterations of the monosaccharides are the opposite of those seen after addition of physiological amounts of insulin (20).
It was not possible to reveal any effect of growth hormone on the incorporation of amino sugars using radioactive glucose as a precursor. However, when tritiated glucosamine was utilized growth hormone reduced the incorporation significantly. This observation is in agreement with our previous data showing a reduced incorporation of radioactive sulfate into the BM-like material after having added growth hormone to the arterial smooth muscle cells in culture (11). The findings are also compatible with the results demonstrating a reduced content of heparan sulfate proteoglycan in the basement membrane from kidneys obtained from individuals with diabetes mellitus (21).

From our analysis, it was observed that mannopyranoside increased the release of radioactive labeled glycopeptides obtained from growth hormone cultures and fractionated on ConA Sepharose columns. It is well known that ConA binds with affinity to the core trimannoside moiety 3,6-di-O-( $\alpha$-D-mannopyranosyl)$\alpha$-D-mannopyranoside which is present in all asparagine-linked carbohydrates $(16,22) . \alpha$-mannosidase treatment of the glycopeptides eluted in peak 3 from the ConA Sepharose column prevented the binding, as demonstrated by rechromatography (14). It cannot be ruled out that the reduced incorporation of glucosamine resulted in few $\beta$-1,4-linked $\mathrm{N}$-acetylglucosamine residues on the $\alpha$-1,6-linked mannose. This will increase the association constant to the ConA Sepharose and therefore retain more glycopeptides in the column (23).

It came to light that the proportions of glycopeptides released from the Pea lectin column was increased after growth hormone treatment. This type of lectin binds certain triantenary glycopeptides, which contain internal fucose residues. However, interaction can also be seen between the lectin and branched carbohydrate structures, which contain an $\alpha$-mannose residue substituted at positions C-2 and C-6 (16). Therefore, the present data suggests a rise in the proportion of triantenary glycopeptides containing either mannosyl groups substituted at positions $\mathrm{C}-2$ and $\mathrm{C}-6$ or fucose residues.

The physiological role of the carbohydrate components in the arterial BM-like material or in other glycoproteins is partly unclear. However, it has been shown that sugar is important for the degradation (24). It appears that removal of either glucose or mannose gives a statistically significant increase in the degradation rate of BM-like material (8). Moreover, in a previous study the degradation rate of the basement membrane from the arterial smooth muscle was inhibited after incubation of the cells with growth hormone (11). Therefore, this reduced degradation is compatible with the observed changes in the carbohydrate unit in the BM-like material. The previous data and the present results suggest that growth hormone is of importance for the metabolism of extracellular matrix components 
through changes in the carbohydrate units as seen in the BM-like material in the blood vessels.

\section{Acknowledgements}

The authors wish to thank Ms Merete Dixen for technical assistance. The present study was supported by the Danish Medical Research Council grant no. 9600822 (Aarhus University-Novo Nordisk Center for Research in Growth and Regeneration).

\section{References}

1 Møller N, Jørgensen JO, Alberti KG, Flyvbjerg A \& Schmitz O. Short-term effects of growth hormone on fuel oxidation and regional substrate metabolism in normal man. Journal of Clinical Endocrinology and Metabolism 199070 1179-1186.

2 Østerby R. Lessons from kidney biopsies. Diabetes/Metabolism Reviews 199612 151-174.

3 Jensen HK \& Ledet T. Proteolysis of arterial basement membrane containing different amounts of carbohydrates. Thrombosis Research 198644 47-53.

4 Hansen AP. Abnormal serum growth hormone response to exercise in juvenile diabetics. Journal of Clinical Investigation 1970 49 1467-1478.

5 Fryburg DA, Gelfand RA \& Barrett EJ. Growth hormone acutely stimulates forearm muscle protein synthesis in normal humans. American Journal of Physiology 1991260 E499-E504.

6 Takeda S, Podskalny JM \& Gorden P. Direct effect of human growth hormone to inhibit glucose uptake in cultured human fibroblasts. Metabolism 198433 658-661.

7 Møller N. The role of growth hormone in the regulation of human fuel metabolism. In Growth Hormone and Insulin-like Growth Factor-I in Human and Experimental Diabetes, pp 77-108. Eds A Flyvbjerg, H Ørskov \& KGMM Alberti. Chichester: John Wiley and Sons, 1993

8 Heickendorff L \& Ledet T. Arterial basement membrane-like material isolated and characterized from rabbit aortic myomedial cells in culture. Biochemical Journal 1983211 397-404.

9 Heickendorff L \& Ledet T. Glycosaminoglycans of arterial basement membrane-like material from cultured rabbit aortic myomedial cells. Biochimica et Biophysica Acta 1984798 276-282.

10 Heickendorff L. Laminin, fibronectin and type IV collagen in BMlike material from cultured arterial smooth muscle cells. International Journal of Biochemistry 198820 381-386.

11 Ledet T \& Heickendorff L. Growth hormone effect on accumulation of arterial basement membrane-like material studied on rabbit aortic myomedial cell cultures. Diabetologia $198528922-927$.
12 Ledet T. Growth hormone stimulating the growth of arterial medial cells in vitro. Absence of effect of insulin. Diabetes 197625 1011-1017.

13 Spiro RG. Studies on the renal glomerular basement membrane preparation and chemical composition. Journal of Biological Chemistry 1967242 1915-1922.

14 Heickendorff L \& Ledet T. Oligosaccharides of arterial basement membrane-like material studied on rabbit aortic myomedial cells in culture. Thrombosis Research 198748 269-278.

15 Cummings RD \& Kornfeld S. Fractionation of asparagine-linked oligosaccharides by serial lectin-agarose affinity chromatography. A rapid sensitive and specific technique. Journal of Biological Chemistry 1982257 11235-11240.

16 Cummings RD \& Kornfeld S. Characterization of the structural determinants required for the high affinity interaction of asparagine-linked oligosaccharides with immobilized Phaeseolus vularis leukoagglutinating and erythroagglutinating lectins. Journal of Biological Chemistry 1982257 11230-11234.

17 Spiro RG. Studies on the renal glomerular basement membrane: nature of the carbohydrate units and their attachment to the peptide portion. Journal of Biological Chemistry $19672421923-$ 1932.

18 Heickendorff L \& Ledet T. The carbohydrate components of arterial basement-membrane-like material: studies on rabbit aortic myomedial cells in culture. Biochemical Journal 1983211 735-741.

19 Spiro RG. The structure of the disaccharide unit of the renal glomerular basement membrane. Journal of Biological Chemistry $19672424813-4823$.

20 Ledet T \& Heickendorff L. Insulin, ketones, glucose and glucagon: effects on the arterial basement membrane in vitro. Acta Endocrinologica 1987115 139-143.

21 Parthasarathy $\mathrm{N} \&$ Spiro RG. Effect of diabetes on the glycosaminoglycan component of the human glomerular basement membrane. Diabetes 198231 738-741.

22 Gupta D, Oscarson S, Raju TS, Stanley P, Toone EJ \& Brewer CF. A comparison of the fine saccharide-binding specificity of Dioclea grandiflora lectin and Concanavalin A. European Journal of Biochemistry 1996242 320-326.

23 Baenziger JU \& Fiete D. Structural determinants of Concanavalin A specificity for oligosaccharides. Journal of Biological Chemistry $19792542400-2407$.

24 Heickendorff L \& Ledet T. Increased degradation of carbohydratedeficient arterial basement membrane-like material from 2-deosyglucose-modified myomedial cell cultures. International Journal of Biochemistry 198618 297-303.

Received 6 October 1999

Accepted 11 February 2000 